\title{
Analysis on the Evolution of Piano Playing Techniques
}

\section{Dengbin Gao}

\author{
China West Normal University, Nanchong, Sichuan, 637000
}

Keywords: piano playing; play techniques; evolution

\begin{abstract}
It has been almost three centuries since the birth of the piano. At the beginning of its development, piano keyboards have not been taken seriously. The ideological trend during the Romantic period slowly influenced the European literary world, and further penetrated into the music art. This new trend that focuses on personal thoughts and feelings caused the old-fashioned keyboard instrument to gradually withdraw, and the piano became the mainstream in the 18th century with its outstanding performance. After a century of development and evolution, the emergence of a large number of piano masters has brought the piano development to a climax. Weber, Mendelssohn, Schubert, Schumann, and other musicians of the Romantic period inherited the foundation of classicalism. By combining contemporary cultural works, they changed their playing techniques.
\end{abstract}

\section{Introduction}

The development of modern pianos has gone through a long period of time, from the earliest organ to the stringed keyboard instrument. From the ancient piano to the piano, and even more than 150 years of development and renewal of the piano itself, it is a hundred schools of thought, resulting in many different forms and branches. Different from the upgrading of current technology products, the replacement of old and new musical instruments is not a rapid vertical replacement. It does not mean that the later piano is more advanced [1]. In general, the piano produced at a specific time and place is definitely suitable for playing that time. And the location of the works. In this process, the playing techniques of the keyboard instrument are slowly adapting to the changes from the old instrument to the new instrument. The performance technique of the piano relies heavily on the improvement and development of the instrument in the early stage, and the composer's creative technique The constant innovation and the increasing difficulty of playing techniques also place higher demands on the piano makers' piano manufacturing. It can be said that the development and evolution of piano skill techniques has a mutually reinforcing influence on the development and evolution of the piano itself. Tight times. After almost a hundred years of development, the piano has been very different from the early piano. Its major changes and reforms are reflected in the linkage mechanism and the production materials. In the romantic period, the piano system has been basically established. In this period, the grand piano lays an important material foundation for the composer's creation and the development of playing techniques. The instrument plays a fundamental role in the technique. In the romantic period, the great changes in the piano also make the piano playing techniques. It is very different from the early piano. In the romantic period, more and more people learn piano, but the oversized body of a grand piano limits its popularity as a family piano. Therefore, a small piano that takes up little space and is comparable to a grand piano is more important. Although upright pianos have the ability to be comparable to grand pianos, their mechanical structure is very different, especially the mechanism of the weak pedal, which leads to some differences in performance. Therefore, the romantic period composer Still choose to use the grand piano for their creation and performance. Although some playing techniques are not as perfect as those on grand pianos, they do not hinder the development and evolution of piano techniques. Upright pianos have indelibly contributed to modern piano teaching and popularization. contribution [2]. 


\section{Improvement of Piano Instruments}

Piano musical instruments were first born in the early 18th century. At the time of Romanticism, piano instruments have undergone historical changes and development for about a hundred years. In these relatively long historical development times, the piano instruments themselves are In fact, the appearance of the shape system has undergone a significant change in objectivity, which has played an important role in the study of the evolution of the piano playing technique in the romantic period. The grand piano was first used by Robert Toddat in 1777. After the time passed into the Romantic period, the grand piano began to be widely used in various types of music; the grand piano was in concert. The establishment of an important position in China was inextricably linked to the two basic events. The first was the invention of the French technician Sebastian Erhard in 1822 for the invention of the "double escapement and linkage mechanism." In fact, this The invention of a technical apparatus more effectively improves the speed of the recovery technical movement of the hammer in the internal operating structure of the original piano musical instrument, and makes it possible to achieve the objective possibility of performing the process of rapidly repeating the musical performance in the process of using the piano musical instrument. The second is the widespread use of metal frames in the manufacturing process of piano instruments. This is in fact a certain degree of objective impact on the original concept of craftsmanship, because it has always been in the concept of the original luthier [3]. It is believed that the introduction of a metal frame during the manufacturing process of a piano instrument will have a significant impact on the timbre conditions of the piano instrument. In this regard, the introduction of the metal frame is a significant impact on the original concept construction level. It is also an important objective reason for promoting the status of the grand piano in the instrument family. After entering the romantic period, more and more people are engaged in the learning of piano instruments. However, the huge physical features of the grand piano have brought a certain degree of practical obstacles to many people who want to engage in piano learning behaviors. In this technical background, the emergence and invention of upright pianos provide the learners with convenience. The modern academic research community generally believes that the American luthier, Domenico del Mela, pioneered the invention of the world's first upright piano in 1739. After the time passed until 1795, it was based on a square piano. Pianos first entered the British market and began to enter the sales process. These are the earliest records of upright pianos in the searchable historical data. From an overall point of view, upright pianos have good mechanical properties comparable to grand pianos, but they also have new technical components and practical features represented by mute pedals, although in terms of performance, the upright piano ratio There is a certain degree of difference in the original grand piano, but the invention and extensive promotion of the upright piano also made important objective contributions to the world-wide piano art and piano teaching.

\section{Analysis of the Evolution of Piano Playing Techniques}

Chopin's exquisite touch-key technology, exquisite timbre changes, the application of color to the pedal and the reasonable and delicate handling of the free speed, will play the piano's internal expressions incisively and vividly. In Chopin's performance method, his means of transport is more unique, breaking the traditional rules and regulations, enabling the big finger black keys, the thumb drilled under the little finger, the same finger from black keys to white or white keys to white keys, etc. Liszt further excavated the performance of the piano on the basis of his predecessors and formed a unique set of skills. Such as accurate octave, big chord jumping, rapid third, sixth, and octave passing phrases, octaves with alternating octaves (i.e., "Leste octaves"), fast fins, high pitch rapid decoration groups, etc. When Liszt played, he often lifted his hands and arms very high and his body's movements were very large. He sought to use the greatest momentary strength to play a bold, loud attack, pursuing a symphonic sound. Brahms played new techniques such as the extreme stretching of his fingers, the little finger across the thumb, and the big jump of the pitch in the piano performance, and pushed the piano playing method forward one step further [4].

Liszt, as a master who profoundly explored the performance potential of the piano, had a 
complete transformation of the entire performance skills of the piano player, in his handling of the effects of piano banding and the difficult skill requirements of his work. It is difficult to rely on finger technology to perform the piano music works of this period perfectly. It requires that the player's arms, shoulders, torso, and all other muscles associated with playing be coordinated. Each movement of the finger has an association with the entire movement of the arm. For the chords and the large-span tones for playing a greater degree of force, the player needs to find his own posture and special fingerings, and each rhythm and strength changes. All echoes the rhythm of the heart. At the beginning of the 19th century, when the "finger school" continued to use its teaching methods to teach students, their students would also have a restless factor. These students generally have a musical talent. They do not listen to the so-called "traditions" and "experiences." These talented students, who know how to think, they will find their own ways to practice, and sometimes they will even work with their own tutors. There are opposite situations. These highly gifted students, who have their own instincts and their own ideas, can abandon the shackles of the old school. In thinking and trying, they will find that they will put aside their fingers and use their arm strength to join in. With the help of the body, the skills can also be improved. Therefore, they are getting wider and wider on the road to become masters. After these students became masters, they began to teach their students in a new and progressive perspective. "Piano poet" Chopin himself does not like to teach piano lessons. Even if she pays little attention to piano education, some of his teaching ideas are very unique. He believes in the importance of the hand, wrist, and arm. He regards the entire upper body as an integral whole. It is recommended that when playing a scale or a melody with a large span, the arm should move along with the hand along the keyboard. He teaches various different touch keys and performance methods and is embodied in his works. Perhaps it is related to his personal style. Chopin pays special attention to legato and song performance. He advises students to learn on the piano. In the singing, the performers should listen to the singing of excellent singers and even try to understand them by themselves. Robert Schumann believes that whether a person can "listen" to his or her own performance is a must-have competitor's ability. He suggested that performers must first understand the nature of listening to a work as a whole, rather than tearing it off as a "section" of mechanical work. Schumann once wrote: "Fingers need to adapt to the will of the brain and cannot go in the opposite direction." "Before you can't hear (not understand) this musical piece in your heart, don't play it." According to Liszt, "The skills do not need to be practiced, but they need to rely on the practice skills." "After listening to the analysis skills, the difficulty in music is converted into some basic forms. The performer who masters this ability has the performance to play this instrument. The ability to write any work." The teaching ideas and methods of the above masters have been disseminated and promoted in the primary development of the 20th century as the "applied psychology school". The use of "hearing" has a significant role in the training of music expression [5]. The ultimate goal of all musical works is to satisfy people's aesthetic needs, and for music works, the satisfaction of aesthetic demands must be achieved through hearing, no matter how skillful each performer is, the speed of playing. How fast is it, if he does not feel happy to express the musical connotation of a musical composition, then he is not a full-fledged performer. Especially in the late romantic period, in the works of French Impressionism, the requirements for timbre are getting higher and higher. At this time, in the training of the piano, auditory training is added, and after the player has mastered certain playing techniques, People need to use a lot of hearing, whether it is the first auditory imagination or the direct sound feedback. They must use the touch keys and touch keys to guide and adjust the sounds.

\section{Conclusion}

The period of romanticism was an important Lishui period of the development of European literature and art. During this period, the piano art realistically obtained relatively clear and objective and far-reaching development results. The research results surrounding related issues can be described as exceptionally rich. 


\section{References}

[1] Xi Yue. The evolution of piano playing techniques in romantic times [D]. Shaanxi Normal University, 2013 - 05 - 01.

[2] Zhang Yan. The development of piano playing techniques in romantic times [J]. Music Time, 2014 - 07 - 30.

[3] Shang Jianye. On the Influence of the Evolution of Piano Style on Piano Technique [D]. Southwest Jiaotong University, 2013 - 05 - 01.

[4] Ma Siqi. Talking about the influence of the evolution of the style of piano works on piano techniques [J]. Arts and Technology, 2014 - 08 - 15.

[5] Jia Yihong. Different stages of piano performance analysis [J]. Stage, 2014 - 10 - 20. 